\title{
Función de la barrera intestinal. Implicancia en la enfermedad celíaca.
}

\author{
Gut barrier function. Implication in celiac disease.
}

\author{
Silvina S. M. Villanueva ${ }^{1}$, Virginia G. Perdomo ${ }^{2}$, Fabiana García ${ }^{3}$ \\ ${ }^{1}$ Instituto de Fisiología Experimental (IFISE-CONICET). Facultad Ciencias Bioquímicas y \\ Farmacéuticas. Universidad Nacional de Rosario. Rosario; Argentina. \\ ${ }^{2}$ Área Parasitología. Facultad de Ciencias Bioquímicas y Farmacéuticas. Universidad Nacional de \\ Rosario-CONICET. Rosario; Argentina. \\ ${ }^{3}$ Laboratorio de Fisiología Metabólica. Facultad de Ciencias Médicas. Universidad Nacional de \\ Rosario-CONICET. Rosario; Argentina.
}

\begin{abstract}
Autor por correspondencia: Fabiana García - fgarcia@fmedic.unr.edu.ar Conflicto de intereses: no presenta.
\end{abstract}

\section{Resumen}

En la mucosa intestinal se encuentra el mayor y más dinámico entorno inmunológico del cuerpo. Es el primer sitio de exposición a patógenos, pero al mismo tiempo está constantemente expuesta a antígenos ambientales inocuos, partículas de alimentos y microflora comensal que necesitan ser tolerados. Por lo tanto las funciones principales del sistema inmune de las mucosas son la inducción de tolerancia (o no reacción) frente a antígenos inocuos y bacterias comensales así como el desarrollo de una respuesta inmune contra los patógenos. En este contexto las respuestas de hipersensibilidad contra los antígenos de la dieta pueden conducir a trastornos inflamatorios como la enfermedad celíaca.

Por lo tanto el objetivo de esta revisión es proporcionar una descripción general de la literatura reciente sobre el mantenimiento de la homeostasis en la mucosa intestinal y del estado de enfermedad que puede sobrevenir cuando se pierde este equilibrio.

Palabras claves: Sistema inmune. Intestino. Enfermedad celíaca.

\begin{abstract}
The intestinal mucosa is the largest and most dynamic immune environment of the body. It is the first site of exposure to pathogens, but at the same time it is constantly exposed to harmless environmental antigens, food particles and commensal microflora that need to be tolerated. Therefore, the main functions of the mucosal immune system are the induction of tolerance (or non-reaction) against innocuous antigens and commensal bacteria as well as the development of an immune response against pathogens. In this context, hypersensitivity responses against antigens in the diet can lead to inflammatory disorders such as celiac disease.

Therefore the aim of this review is to providean overview of the recent literature on the maintenance of homeostasis in the intestinal mucosa and the disease state that can ensue when this balance is lost.

Keywords: Immune system. Intestine. Celiac Disease.
\end{abstract}




\section{Sistema inmunitario intestinal}

Las superficies mucosas están presentes en sitios donde los tejidos interactúan o son contiguos al ambiente externo. Algunos ejemplos incluyen el tracto gastrointestinal, el árbol pulmonar y el tracto genitourinario (1).

La mucosa gastrointestinal es una barrera semipermeable que permite el flujo de agua, iones, solutos, incluida la absorción de nutrientes, la regulación de la homeostasis del cuerpo y la detección inmune, al tiempo que limita el paso de antígenos y microorganismos potencialmente dañinos desde la luz intestinal. Este sistema complejo incluye, desde la superficie luminal hasta la basolateral, la microbiota intestinal, la capa de moco, la capa epitelial intestinal, la lámina propia y el tejido linfoide asociado al intestino (GALT). Además, el GALT se compone de diferentes entidades de tejidos linfoides organizados que incluyen las placas de Peyer (PP), los folículos linfoides aislados (ILF) y los ganglios linfáticos mesentéricos (MLN) (1-3). El sistema inmunitario intestinal constituye la parte más extensa y compleja del sistema inmunitario. Diariamente enfrenta desafíos distintos a otros órganos ya que recibe una gran carga antigénica pero también debe discriminar entre organismos invasores y antígenos inofensivos, como las proteínas alimentarias y las bacterias comensales $(4,5)$. Esta carga antigénica enorme y altamente variable ha resultado en una distribución estratégica de células involucradas en la captación, procesamiento y presentación de antígenos; producción de anticuerpos; y defensas mediadas por células. Los datos cuantitativos son demostrativos tiene más macrófagos, células plasmáticas y células T que cualquier otro tejido linfoide del sistema inmunitario (4).

La defensa inmunitaria de la mucosa se puede dividir en sitios inductores y efectores. En los sitios inductores, se realiza el procesamiento e inicio de la respuesta inmune, allí los antígenos captados de la superficie mucosa activan a los linfocitos en las PP, ILF y MLN que luego vuelven a la circulación vía ganglios mesentéricos y conducto torácico. (1, 6-8). En los sitios efectores, tanto en el epitelio como en la lámina propia, los linfocitos efectores se encuentran dispersos por todo el tejido para realizar su acción (1, 3, 6-8).

La restauración de la homeostasis inmune de la mucosa intestinal después de la exposición a patógenos depende de un conjunto complejo y coordinado de respuestas innatas y adaptativas. La especialización inmunitaria específica se basa además en la capacidad de las células inmunes para integrar las señales locales provenientes de los productos microbianos, metabolitos o nutrientes. Estas redes son esenciales para la inducción de una respuesta inmunitaria adecuada preservando los requisitos fisiológicos del tejido (9).

Esta revisión, desarrolla como son coordinadas e inducidas las respuestas inmunes en el GALT a su vez que menciona la alteración en la función de barrera que se presenta en la enfermedad celíaca.

\section{Rol de la barrera epitelial intestinal}

El epitelio intestinal está compuesto por una capa de células epiteliales intestinales (IEC) organizada en criptas y vellosidades (Figura 1) (10). Se renueva cada semana a partir del nicho de células madre epiteliales intestinales (IESC) que residen en la base de las criptas, diferenciándose en múltiples tipos de células intestinales epiteliales como las células caliciformes (células de Goblet), las células enteroendocrinas, los enterocitos, las células de Paneth y las células Microplegadas (células M). Las IEC diferenciadas, con excepción de las células de Paneth, migran en el sentido cripta-vellosidad (11-12). 


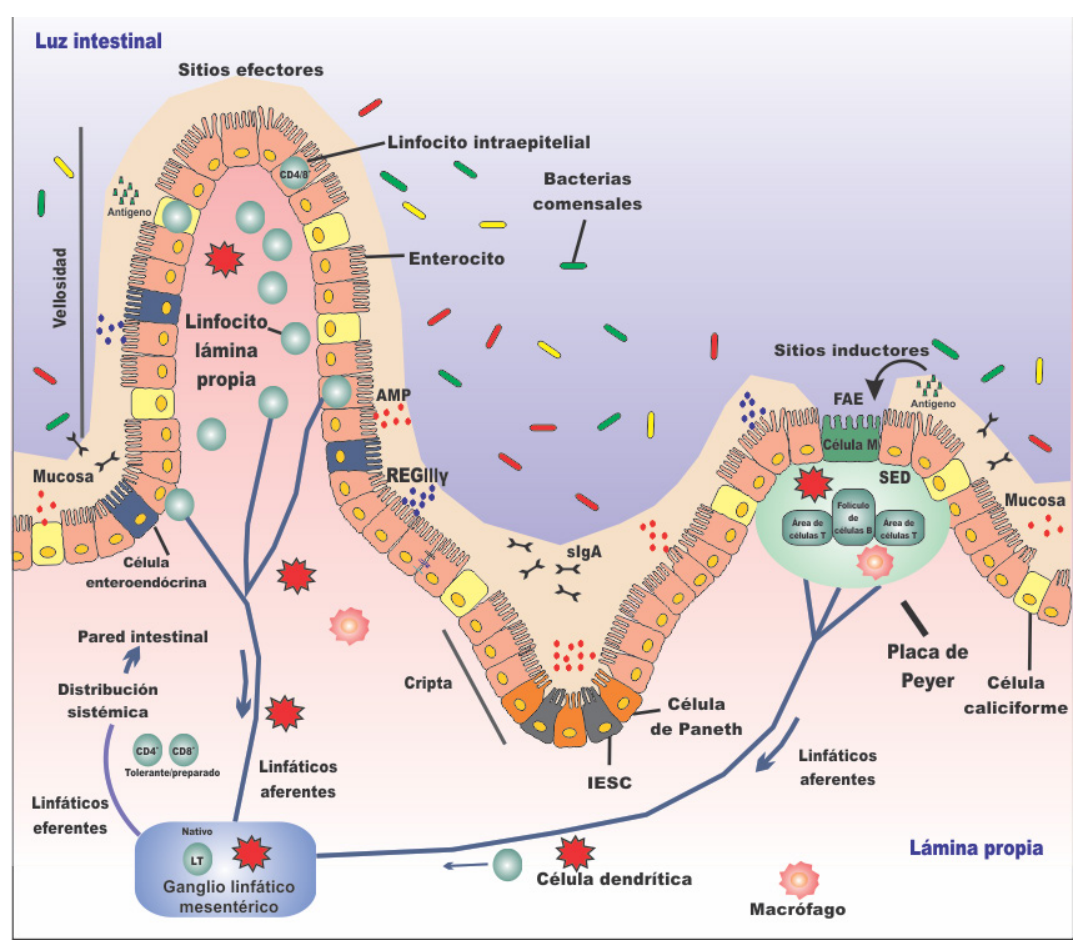

Figura 1. Representación esquemática del sistema inmunitario intestinal. Las células epiteliales intestinales y la capa mucosa forman una barrera física y bioquímica que mantiene la segregación entre la luz intestinal y el sistema inmune de la mucosa. El tejido linfoide asociado al intestino comprende los tejidos linfoides organizados de las placas de Peyer y los ganglios linfáticos mesentéricos, que son los sitios principales para la inducción de las respuestas inmunitarias, mientras que la lámina propia y la capa epitelial se consideran sitios efectores. Las placas de Peyer y la lámina propia son drenados por los linfáticos aferentes que van al ganglio linfático mesentérico. En conjunto, la barrera epitelial, el tejido linfoide organizado, las células inmunes dispersas a través de la lámina propia y el epitelio forman los componentes primarios del sistema inmunitario intestinal. FAE: epitelio asociado a los folículos; Célula M: célula de micropliegues; SED: domo subepitelial; AMP: péptidos antimicrobianos; REGIII $\gamma$ : la proteína III $\gamma$ derivada de los islotes regeneradores de lectina de tipo C. sIgA: IgA secretora; IESC: células madre epiteliales intestinales (Adaptado de Ahluwalia B et al., 2017)(2).

La principal barrera física y bioquímica la forma la capa mucosa junto con las IEC (10,13). La interfaz entre los dominios de la membrana apical y basolateral está delimitada por una compleja red de proteínas que, desde la superficie apical hasta la basolateral, está compuesta por uniones estrechas (zonula occludens), uniones adherentes (zonula adherens) y desmosomas (Figura 2) (1,1415). La expresión de estas proteínas de unión en el intestino está altamente regulada y es importante para mantener la integridad del epitelio intestinal y la permeabilidad intestinal (2). Las uniones adherentes y los desmosomas no sellan el espacio entre las células epiteliales, pero proporcionan las fuerzas adhesivas necesarias para el mantenimiento de las interacciones célula-célula. El componente más conocido de las uniones adherentes son las cadherinas, en el lado citoplásmico, las cadherinas interactúan con $\alpha$-catenina y $\beta$-catenina. Entre otras funciones, la a — catenina y la Ecadherina regulan el ensamblaje de la actina en la unión celular proporcionando mayor resistencia a estas estructuras. La unión estrecha es el principal determinante de la permeabilidad paracelular. Las uniones estrechas sellan el espacio a través las proteínas transmembrana claudina y ocludina, y las proteínas adaptadoras citoplasmáticas tales como zonulinas (ZO-1). Hay dos rutas distintas a través de las uniones estrechas de una monocapa epitelial intacta, denominadas "poro" y "fugas". La vía del poro se refiere a una vía altamente selectiva en función del tamaño y la carga, mientras que la vía de fuga es una vía de baja capacidad que tiene una selectividad limitada. La permeabilidad de la vía del poro parece estar determinada principalmente por el subconjunto de claudinas, mientras que la permeabilidad de la vía de fuga puede ser regulada por $\mathrm{ZO} — 1$, ocludina y la quinasa de cadena ligera de miosina. Durante la homeostasis el epitelio está intacto y la función de barrera refleja el flujo a través de las vías de poro y fuga paracelulares $(1,14-16)$.

La función de la barrera intestinal se ha asociado con una variedad de enfermedades intestinales como sistémicas, y ha llevado a popularizar el diagnóstico de "síndrome del intestino permeable". $\mathrm{Si}$ bien la gran mayoría de estas asociaciones son meramente correlativas, en algunos casos hay 
evidencia experimental que relaciona la disfunción de la barrera con la patogénesis de la enfermedad, entre ellas la enfermedad inflamatoria intestinal y la enfermedad celíaca (17).

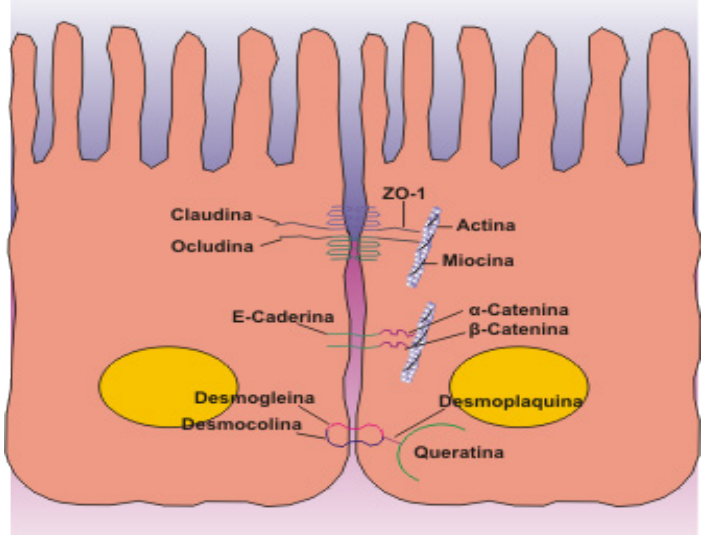

Figura 2. Representación esquemática del complejo de unión apical para la formación de la barrera epitelial. Las células epiteliales individuales se mantienen juntas y se comunican entre sí a través de una serie de uniones dentro del complejo de unión apical. El complejo de la unión apical se coloca cerca de la superficie apical a lo largo de la membrana lateral y está compuesto por la unión estrecha, la unión adherente y los desmosomas (Adaptado de Odenwald MA, Turner JR, 2013)

\section{Células epiteliales intestinales guardianas de la homeostasis intestinal}

Un aspecto fundamental de las IEC para mantener las funciones de barrera e inmunorreguladoras es su capacidad para actuar como sensores de primera línea para los microbios e integrar las señales derivadas de las bacterias comensales en respuestas antimicrobianas e inmunorreguladoras. Las IEC expresan receptores de reconocimiento de patrones (PRR), miembros de los receptores tipo Toll (TLR), receptores tipo NOD (NLR) y familias de receptores tipo RIG-I (RLR), los cuales proporcionan distintas vías para el reconocimiento de ligandos microbianos o señales endógenas asociadas con la patogénesis (18-20). A diferencia de los sitios estériles en el cuerpo donde el reconocimiento de los microorganismos extraños inicia cascadas altamente inflamatorias, la abundancia de comensales simbióticos en el intestino requiere que las IEC mantengan la señalización de los PRR con una respuesta baja frente a los estímulos de las bacterias comensales (21). En apoyo de esto, las IEC expresan reguladores negativos de la señalización proinflamatoria dependiente de los $P R R(21,22)$. Además, según algunos estudios, la producción de especies reactivas del oxígeno por las IEC, dependiente de las bacterias comensales, atenuaría la activación de $\mathrm{NF}-\kappa \mathrm{B}$ (factor nuclear cercano al gen de cadena ligera $\kappa$ en las células B) tolerando de este modo la estimulación microbiana a través de la señalización PRR (23). Las células epiteliales intestinales además de mantener una baja reactividad, deben diferenciar entre señales derivadas de microorganismos comensales y patógenos para una respuesta inflamatoria adecuada (24). La naturaleza polarizada del epitelio intestinal permite la segregación anatómica de los PRR. Los modelos in vitro e in vivo demuestran una respuesta diferencial de las IEC a la estimulación apical frente a la basolateral con múltiples ligandos TLR (25-26). Por ejemplo, aunque la exposición basolateral de las IEC a ligandos de TLR9 da como resultado la activación canónica y la translocación nuclear de $\mathrm{NF}-\kappa \mathrm{B}$, la exposición apical produce un efecto inhibidor a través de la estabilización de IкB (26). Esta señal apical induce tolerancia a la estimulación posterior de TLR demostrando una adaptación única para la tolerancia cruzada de las vías de reconocimiento microbiano y una respuesta diferencial a señales microbianas basada en la ubicación anatómica. Este concepto de segregación subcelular y distribución polarizada de TLR se ha traducido también a la regulación de vías PRR adicionales (26).

\section{Defensas secretoras del epitelio y componentes celulares involucrados}

Aunque el epitelio intestinal está involucrado principalmente en la absorción de nutrientes, contiene células especializadas, que llevan a cabo diversas funciones y juegan un papel importante en la regulación de las respuestas inmunes en el tracto gastrointestinal. En conjunto, las diversas funciones de las IEC dan como resultado una barrera dinámica al medio ambiente, que protege al huésped de la infección y la exposición continua a estímulos potencialmente inflamatorios (10). La 
secreción luminal de mucinas y proteínas antimicrobianas (AMP) por las células caliciformes y las células de Paneth, respectivamente, estableceuna barrera bioquímica del entorno microbiano con la superficie epitelial y las células inmunes subyacentes (27-28) (Figura 1). Los enterocitos son capaces de producir algunas AMP, como la proteína III $\gamma$ (REGIII $\gamma$ ) derivada de los islotes regeneradores de lectina de tipo C, en todo el intestino delgado y el colon. Por el contrario, las células de Paneth están adaptadas únicamente para la secreción de AMP, incluidas las defensinas, catelicidinas y lisozima, en las criptas del intestino delgado $(13,28,29)$. La secreción de mucinas altamente glucosiladas en el lumen intestinal por las células caliciformes crea la primera línea de defensa contra la invasión microbiana. La más abundante de estas mucinas, la mucina 2 (MUC2), juega un papel esencial en la organización de las capas mucosas intestinales en la superficie epitelial del colon (29). La importancia de la producción de mucina se enfatiza por el desarrollo espontáneo de colitis y la predisposición a cánceres colorrectales inducidos por inflamación observados en ratones deficientes en MUC2 (30). Similar a la función y regulación de MUC2 en el colon, REGIII $\gamma$ actúa para excluir bacterias de la superficie epitelial del intestino delgado, y su producción depende del reconocimiento intrínseco de las IEC de señales microbianas comensales (31). La capa mucosa, según su ubicación en el tracto gastrointestinal, está organizada para crear la primera línea de defensa contra la invasión microbiana. El intestino delgado tiene una capa mucosa delgada penetrable para permitir la absorción de nutrientes, mientras que el colon, que presenta comparativamente un número mayor de bacterias residentes y carece de células de Paneth, tiene una barrera mucosa de dos capas con una capa mucosa interna densa sin bacterias $(2,10,29)$. La producción de moco está controlada por mediadores inmunitarios que incluyen leucotrienos, interferón- $\gamma$ (IFN $\gamma)$, IL—9 e IL-13. El moco tiene funciones antimicrobianas, formando un gel altamente cargado que actúa como una barrera física, además está compuesto por glucoproteínas de mucina que son directamente tóxicas para muchas bacterias. El glucocálix más suelto del intestino delgado también proporciona una matriz a la que pueden adherirse los anticuerpos y los péptidos antimicrobianos (32).

Las interacciones entre las AMP, incluido REGIII $\gamma$, y las mucinas conducen a una actividad antimicrobiana concentrada en la superficie epitelial (10). Por tanto, las funciones combinadas de las IEC secretoras parecen limitar la cantidad y diversidad de bacterias vivas que pueden alcanzar la superficie epitelial e interactuar con el sistema inmunitario de la mucosa subyacente.

Por último, las IEC transportan directamente inmunoglobulinas secretoras a través de la barrera epitelial. Después de su producción por las células plasmáticas en la lámina propia, los complejos de IgA diméricos se unen al receptor de inmunoglobulina polimérico (pIgR) en la membrana basolateral de las IEC y por transcitosis llegan a la luz intestinal (33).

La colaboración entre las células B secretoras de IgA y las IEC proporciona un componente inmunitario adaptativo a la barrera epitelial que regula las poblaciones bacterianas comensales para mantener la IEC y la homeostasis de las células inmunitarias (34). La IgA secretora (sIgA) representa el sello distintivo de la respuesta inmune en la mucosa y contribuye a la homeostasis a través de una variedad de mecanismos (35). Los anticuerpos de sIgA son inducidos por la exposición postnatal a microorganismos comensales, esto indica que juegan un papel en la detección de los microbios comensales y limitan su sobrecrecimiento $(36,37)$. Los anticuerpos sIgA también protegen al huésped al unirse a la superficie de microbios luminales y toxinas para evitar que se adhieran a las células epiteliales (Figura 1) (38). Este mecanismo de exclusión limita la capacidad de los patrones moleculares asociados a patógenos microbianos para desencadenar respuestas inflamatorias y, por lo tanto, contribuye al efecto antiinflamatorio de sIgA. Aunque la inducción de sIgA es deseable para una óptima protección de las superficies mucosas y la limitación de las infecciones sistémicas, la producción de estos anticuerpos se regula de forma diferente a la de los anticuerpos IgG e IgA sistémicos, y son mal inducidos por las vacunas convencionales (33). Estudios futuros para comprender mejor cómo se pueden regular el moco, las AMP y la dinámica de las inmunoglobulinas secretoras para respaldar la función de barrera permitirán el desarrollo de intervenciones terapéuticas para preservar la homeostasis intestinal.

Las poblaciones de linfocitos que son residentes no recirculantes de tejidos y órganos no linfoides, se encuentran principalmente en tejidos de barrera, como centinelas y defensores de la integridad del mismo en respuesta a infecciones y a agresiones no infecciosas (39). Estas poblaciones incluyen células $\mathrm{T}$ de memoria residentes en tejidos $\left(\mathrm{T}_{\mathrm{RM}}\right)$; Células $\mathrm{T}$ "no convencionales", como las células $\mathrm{T}$ asesinas naturales invariantes (iNKT), las células T invariantes asociadas a la mucosa (MAIT), las células $\mathrm{T} \gamma \delta$ y los linfocitos intraepiteliales intestinales (IEL); y la familia emergente de células linfoides innatas (ILC). Estos linfocitos residentes en el tejido abarcan un continuo innato-adaptativo pero, 
no obstante, comparten una serie de características particulares relacionadas con sus funciones residentes en el tejido (40-42). Los IEL que están en contacto directo con las células epiteliales y que tienen una proximidad inmediata a los antígenos intestinales, constituyen la primera línea de defensa inmune contra los patógenos invasores $(43,44)$. Los IEL intestinales son células T, que tienen un fenotipo modulado por los antígenos y pertenecen a los linajes del receptor de células $\mathrm{T}-\gamma \delta \mathrm{y}$ TCR—aß (32, 43-45). En los seres humanos, los IEL de TCR—aß constituyen la mayor parte de la población de linfocitos, mientras que los linfocitos con TCR $-\gamma \delta$ constituyen aproximadamente el 10\% de la población total (43-45). Se considera que la retención de los IEL en la capa de células epiteliales se debe a la interacción de la integrina aE $\beta 7$ presente en los linfocitos con la molécula Ecadherina expresada en la superficie basolateral de las células epiteliales (2). Se ha sugerido que los IEL tienen una función importante en el mantenimiento y protección de la barrera de la mucosa y también se han implicado en funciones reguladoras y en el mantenimiento de la homeostasis intestinal como se muestra en varios modelos animales (39, 43, 44, 46).

Al carecer de receptores de antígenos clásicos, las ILC se activan por citocinas. Las ILC similares a los linfocitos auxiliares CD4 ${ }^{+}$se pueden subdividir en los tipos 1, 2 y 3 (ILC1, ILC2 e ILC3) según la expresión diferencial de los factores de transcripción que especifican el linaje T—bet, GATA-3 y ROR $\gamma$ t respectivamente; para producir las citocinas efectoras como interferón- $\gamma$ (ILCl), IL-5 e IL-13 (ILC2) e IL-17 (ILC3). Además de producir citocinas que orquestan y amplifican las defensas antimicrobianas, las ILC también elaboran factores solubles que promueven el mantenimiento de los tejidos. Por ejemplo, diferentes subconjuntos de ILC responden a la citocina proinflamatoria IL—23 o a la alarmina IL—33 produciendo el factor protector de tejidos IL—22 $(40,41)$.

\section{Anatomía del GALT}

Como se mencionó anteriormente la fase inductora de la respuesta inmune está compartimentalizada en las PP, ILF y MLN, mientras que el brazo efector se encuentra en el epitelio y la lámina propia del intestino. En la lámina propia se encuentran la mayoría de las células inmunes, y también contiene la irrigación sanguínea, el drenaje linfático y la inervación nerviosa de la mucosa (32). La lámina propia es un importante sitio efector de la respuesta inmune intestinal y, por tanto, importante para prevenir la entrada y propagación de patógenos a través de la mucosa intestinal y la destrucción de patógenos en caso de una invasión $(43,46)$. Las placas de Peyer originalmente descriptas por Joseph Hans Conrad Peyer en 1677 como "un agregado linfoide macroscópico que se puede ver a simple vista en el lado seroso del intestino delgado”. Están distribuidas a lo largo del intestino delgado, suman 100-200 en humanos y 6-12 en ratones (Figura 1) (48). Las PP son estructuras organizadas que consisten en grandes folículos de células B con áreas intermedias más pequeñas de células T, así como macrófagos y células dendríticas (CD) interpuestas, contenidas en una estructura en forma de cúpula conocida como cúpula subepitelial (SED). La SED está separada de la luz intestinal por un epitelio asociado al folículo (FAE) de una sola capa, que se diferencia del epitelio de la vellosidad intestinal porque tiene niveles más bajos de enzimas digestivas (49). Además de tener vasos sanguíneos, las PP tienen vasos linfáticos que se utilizan como portales de salida para los linfocitos y las células plasmáticas. Las PP están continuamente expuestas a antígenos derivados de la mucosa y sus folículos contienen centros germinales (GC) preformados, que son sitios de hipermutación somática del gen de las inmunoglobulinas y selección de células-B (50). La importancia del microbioma en la promoción de estas respuestas se demuestra por el tamaño del tejido, el cual es mucho más pequeño y hay ausencia de GC en las PP proveniente de ratones libres de gérmenes $(51,52)$. En cambio muchas de las células B presentes en las PP de animales alojados convencionalmente han presentado cambio de isotipo de IgM a IgA, y las PP dan lugar a células plasmáticas IgA que se dirigen selectivamente a la lámina propia intestinal (48). La principal diferencia entre las PP y los ganglios linfáticos es que las PP carecen de linfáticos aferentes y no están encapsulados. Los ILF son similares a las PP pero más pequeños y se encuentran en todo el intestino (53).

En condiciones estables, aproximadamente el 10\% de las células epiteliales dentro del FAE son células M. Son células epiteliales típicas, ya que se orientan a lo largo de la lámina basal, se adhieren a los enterocitos adyacentes mediante uniones apicales estrechas, muestran polaridad con microvellosidades en su superficie luminal y tienen núcleos situados en la base (53). Sin embargo, carecen de un citoesqueleto interno rígido y se deforman fácilmente por la migración de las células linfoides hacia el epitelio. Esto permite la creación de un bolsillo debajo de la célula $\mathrm{M}$ desde el cual las células linfoides pueden entrar y salir sin romper las membranas de las células M. Estos bolsillos pueden dilatarse tanto que las membranas luminal y basolateral de las células M están separadas por sólo un pocas micras de citoplasma. Además, a diferencia de los enterocitos vecinos dentro del FAE, 
las células M están altamente especializadas para la fagocitosis y transcitosis de macromoléculas de la luz intestinal, antígenos particulados y microorganismos patógenos o comensales a través del epitelio. Después de su transcitosis a través del FAE, los antígenos salen al bolsillo intraepitelial debajo de la membrana basolateral de las células $\mathrm{M}$, que contiene varias poblaciones de linfocitos y fagocitos mononucleares (MNP, una población heterogénea de macrófagos y células dendríticas clásicas). Este microambiente especializado debajo de la célula M permite la transferencia eficiente de antígenos luminales a los MNP. Es importante señalar que las células M no solo están restringidas al FAE que cubre el GALT, se han reportado también en el NALT (tejidos linfoides asociados al tracto nasofaríngeo), en el muestreo de antígenos en el tracto respiratorio (54).

Los ILF se describieron por primera vez como 100-200 grupos de linfocitos ubicados a lo largo del intestino delgado. Múltiples observaciones son consistentes en que los ILF actúan como sitios inductores de respuestas inmunes de la mucosa. Al igual que las PP, los ILF poseen un FAE que contiene células M (53).

Los MLN son los ganglios linfáticos más grandes del cuerpo y su función principal es filtrar la linfa proveniente del intestino e iniciar respuestas inmunitarias contra los antígenos llevados por las células mononucleares que migran desde el sitio inductor. Además de un gran número de linfocitos, los MLN contienen macrófagos y células presentadoras de antígenos que interactúan con los linfocitos para su activación (55).

Podemos resumir lo desarrollado hasta el momento como la respuesta innata de la inmunidad intestinal que comprende como primera línea de defensa contra la infección, la superficie epitelial del tracto gastrointestinal, proporcionando una barrera física contra el "exterior". Una segunda línea de defensa es la barrera bioquímica producida por las células epiteliales, que consiste en la síntesis de mucina (células caliciformes o células Goblet), proteínas antimicrobianas (células Paneth e IEC), REGIII $\gamma$ (IEC) y la presencia de inmunoglobulina secretora sIgA, que cubren las superficies epiteliales del tracto gastrointestinal, e impiden que los microorganismos lleguen a sitios sistémicos. Una tercera línea de defensa la proporcionan numerosas células inmunes que residen en el intestino, ya sea en estructuras organizadas, como las placas de Peyer y los ganglios linfáticos mesentéricos, o dispersas por el epitelio intestinal y la lámina propia. Las células del sistema inmune innato, incluyen, neutrófilos, macrófagos, células dendríticas, células asesinas naturales (NK), eosinófilos, basófilos y mastocitos. En los sujetos sanos, las células dendríticas y los macrófagos de la lámina propia del intestino inhiben la inflamación y sirven para mantener la homeostasis. Asimismo los receptores TLR y los receptores citoplásmicos NLR expresados en las células epiteliales intestinales promueven respuestas inmunitarias a los microorganismos patógenos invasores, pero también limitan las respuestas inflamatorias a las bacterias comensales. Además en la mucosa intestinal se encuentran células linfocíticas innatas (ILC3) que producen IL-17 e IL—22 que contribuyen a la defensa inmunitaria frente a algunas bacterias (producción de moco, defensinas y favorecen el transporte de sIgA) así como a la función de barrera de la mucosa epitelial.

\section{Inducción de la respuesta inmune adaptativa}

\section{- Vías de captación del antígeno}

Las respuestas inmunitarias sistémicas y de las mucosas sólo pueden montarse a partir de la entrada del antígeno a los sitios de inducción. Con este fin, existen una serie de mecanismos para el muestreo de antígenos en el contenido luminal. Las células especializadas M transportan macromoléculas y microorganismos a las CD subyacentes en el SED (56). El muestreo de antígenos también se realiza mediante un número menor de células $M$ asociadas a las vellosidades (57), células caliciformes (58), macrófagos que expresan el receptor de quimiocinas $\mathrm{CX} 3 \mathrm{CR}^{+}$residentes en la lámina propia (56) y células dendríticas (59). Las CD, envían dendritas entre las células epiteliales y toman muestras directamente de las bacterias. Además, dado que las CD expresan proteínas de unión estrecha como occludina, claudina y zonula occludens, se conserva la integridad de la barrera epitelial (59). Los macrófagos $\mathrm{CX} 3 \mathrm{CR}^{+}$participan en el muestreo de antígenos extendiendo dendritas transepiteliales (TED) entre las células epiteliales para capturar antígenos o microbios y, posteriormente, transportarlos a través de la barrera epitelial. (56). Los macrófagos 
intestinales $\mathrm{CX} 3 \mathrm{CR}^{+}$responden a distintas señales que se originan en los patógenos, pueden extender las dendritas transepiteliales entre las células epiteliales intestinales para muestrear los microbios e iniciar la respuesta inmune específica. Alternativamente, pueden migrar a la luz intestinal e internalizar los microbios para prevenir que los patógenos atraviesen el epitelio e infectar al huésped. No están claros los eventos que conducen al modo de muestreo o migración; sino que representarían dos funciones distintas de las células $\mathrm{CX} 3 \mathrm{CR} 1^{+}$que probablemente intervienen en diferentes etapas de la infección en distintas áreas del intestino. El muestreo ocurre en el íleon terminal y en el colon, mientras que la transmigración ocurre en todo el intestino delgado pero está ausente en el colon (56).

- Presentación del antígeno y activación de las células inmunes

El reconocimiento de los patógenos captados por las células presentadoras de antígenos (APC) en la cúpula de las placas de Peyer conduce a la secreción de citocinas inflamatorias, quimiocinas, mayor reclutamiento de células inmunes innatas y la activación de las APC. Las APC interiorizan y procesan los antígenos hasta péptidos antigénicos que se expresarán en la membrana plasmática asociados a moléculas del complejo mayor de histocompatibilidad (MHC) de clase I o II (55). Las APC activadas pueden interaccionar con los linfocitos T en las áreas interfoliculares de las PP o dirigirse a través de los vasos linfáticos, hacia al área de células T ubicada en la paracorteza de los ganglios linfáticos mesentéricos para activar los linfocitos T (Figura 1) (6). Las células T experimentan activación y diferenciación mediada por señales específicas de antígeno que se inducen después de la interacción del receptor de células $\mathrm{T}$ (TCR) (2). Las células T-CD8 ${ }^{+}$reconocen péptidos intracelulares presentados por moléculas del $\mathrm{MHC}$ de clase I y las células $\mathrm{T}-\mathrm{CD} 4^{+}$interactúan con péptidos derivados de antígenos presentados por las moléculas del MHC de clase II expresadas en las APC (60). Del mismo modo se necesita una señal coestimuladora de la APC al ligando de células T correspondiente para que las células $\mathrm{T}$ se activen. Las células $\mathrm{T}-\mathrm{CD} 4^{+}$pueden diferenciarse, en función de las citocinas del entorno, en células T-helper 1 (Th1), T-helper 2 (Th2), T-helper 17 (Th17), células $\mathrm{T}$ foliculares helper $\left(\mathrm{T}_{\mathrm{FH}}\right)$ y células $\mathrm{T}$ reguladoras (Tregs). La diferenciación de linfocitos $\mathrm{T}-\mathrm{CD}^{+}$en linfocitos T citotóxicos efectores (CTL) está también mediada por citocinas que incluyen IL-2, IL—12, IL—15 e IL—21 y la ayuda de los linfocitos T colaboradores (60).

- Alojamiento de los linfocitos activados en los sitios efectores

Los linfocitos activados en las PP y MLN migran preferentemente al tejido de la mucosa donde se indujo la respuesta inmune. Estos linfocitos, regulan positivamente la integrina a4 $\beta 7$ y migran al torrente sanguíneo a través del conducto torácico para alojarse en la lámina propia. La integrina a4 $\beta 7$, de los linfocitos B y T se une a la proteína MadCAM-1 expresada en las células endoteliales de las vénulas poscapilares en la lámina propia (60, 61). El alojamiento intestinal también requiere el receptor para quimiocinas CCR9 en los linfocitos B y T y su ligando CCL25, que producen las células epiteliales intestinales. La expresión combinada de MadCAM—1 y CCL25 se limita al intestino $(3,60)$.

\section{- Función efectora de los linfocitos activados}

Al entrar en el tracto gastrointestinal, una fracción de los linfocitos T activados se dirigen a la lámina propia, mientras el resto migra al epitelio $(3,32)$. Las respuestas de las células Thl mejoran la inmunidad contra virus y patógenos intracelulares mediante la producción de las citocinas IFN- $\gamma$ e TNF- a. Las células Th2, que son importantes para la inmunidad humoral y el control de las infecciones por helmintos, secretan citocinas como IL—4, IL-5 e IL-13 que ayudan a inducir la activación y diferenciación de las células B y también estimulan el reclutamiento de eosinófilos y mastocitos a los tejidos (62). Las células Th17, que producen IL-17A e IL—22, desempeñan un papel importante en la respuesta de la mucosa a los patógenos extracelulares $(10,63)$. IL—17A amplifica las respuestas proinflamatorias como la producción epitelial de quimiocinas que promueven el reclutamiento de neutrófilos en el intestino. Además, IL-17A junto con IL-22 amplifica la expresión de proteínas antimicrobianas por las IEC y refuerza la barrera epitelial, evitando así la propagación de las bacterias patógenas (63). Las células T citotóxicas, desempeñan un papel importante 
en la defensa contra patógenos intracelulares, incluidos virus y bacterias, mediada principalmente por la liberación de gránulos citotóxicos como perforina. y granzimas, a través de su capacidad para formar poros en membranas celulares, conducen a la apoptosis de la célula diana. Las células T $\mathrm{CD} 4^{+}$y $\mathrm{CD} 8^{+}$activadas por el antígeno pueden residir como células de memoria efectoras de larga duración en la lámina propia y al reencontrarse con los antígenos específicos en el intestino conducir a la expansión selectiva de estos clones. Las células $\mathrm{T}$ de memoria efectora son capaces de responder rápidamente para ejercer una respuesta rápida contra las células infectadas por patógenos, evitando así la diseminación sistémica (64). Al mismo tiempo las células plasmáticas, que residen en la lámina propia, producen predominantemente sIgA como fue mencionado anteriormente. Es importante destacar que no solo las células B de memoria, sino también las células plasmáticas de larga vida, persisten de por vida, manteniendo la protección mediante la respuesta de anticuerpos antimicrobianos frente a las infecciones (65).

\section{Enfermedad Celíaca}

\section{Características generales}

La enfermedad celíaca (EC) es una enteropatía crónica del intestino delgado mediada por células T que se presenta en individuos genéticamente susceptibles expuestos al gluten y es caracterizada por:

- Malabsorción generalizada: enteropatía malabsortiva.

- Lesiones de la mucosa del intestino delgado: histológicamente se caracteriza por atrofia de las vellosidades y por hiperplasia compensatoria de las criptas.

- Rápidarespuestaclínicaehistopatológicaalretirodealimentosconteniendoglutendela dieta.

Sus numerosas manifestaciones clínicas van desde síntomas gastrointestinales hasta síntomas no gastrointestinales o síntomas mínimos $(66,67)$.

\section{Epidemiología}

La EC se puede evidenciar en cualquier momento de la vida, luego que los cereales se introducen en la dieta. Los estudios iniciales sobre la prevalencia de la EC proceden de Europa, donde afecta a aproximadamente el 1\% de la población europea en general $(68,69)$. Durante las siguientes décadas, los estudios poblacionales confirmaron que la EC también es común en países no europeos con una población predominantemente caucásica, como Estados Unidos (70), Australia (71) y algunos países de América Latina, como Perú, Argentina y Brasil (72). Los estudios de Oriente Medio y Asia Sudoriental, como India y China, informan de una prevalencia similar (73).

En Argentina, estudios publicados en los comienzos del presente siglo han permitido estimar que la prevalencia de la EC entre sujetos adultos de la ciudad de La Plata es equivalente a la estimada para otras poblaciones europeas (74).

De acuerdo a esto, se puede enunciar que la EC es una enfermedad global con una prevalencia que ha ido en aumento en diferentes zonas geográficas del mundo durante las últimas décadas. Este incremento puede atribuirse, en parte, a la mejora en las técnicas de diagnóstico y al mayor conocimiento y conciencia de la EC; sin embargo, estas evidencias no son suficientes para justificar el incremento observado en los últimos 30-40 años. En este contexto, se considera que existe un verdadero incremento de la prevalencia y este podría consistir en una duplicación de casos en los últimos 20 años (74).

\section{Patogénesis}

En la patogénesis de la EC, se indica que la predisposición genética y la exposición al gluten, son factores cruciales en su desarrollo. No obstante, en forma estricta, la patogénesis de la EC se explica por la interacción entre factores ambientales, genéticos e inmunológicos $(75,76)$. 
- Las proteínas del cereal, como factor ambiental, cumplen un rol importante en la patogénesis molecular, dado que existe una asociación directa entre el desarrollo de la EC y la ingestión de gluten, contenido en el trigo, la cebada y el centeno. Las gliadinas y gluteninas, contenidas en el gluten (refiere al componente proteico entero del cereal), tiene un alto contenido de glutaminas y prolinas y son mal digeridas por el tracto gastrointestinal superior de los seres humanos. Las moléculas no digeridas de gliadina y glutetina, son resistentes a la degradación por las proteasas gástricas, pancreáticas y del ribete en cepillo del enterocito (dado que son deficientes en actividad prolilendopeptidasa); por lo tanto, permanecen en la luz intestinal luego de la digestión del gluten. Estos péptidos pasan a través de la barrera epitelial del intestino, por vía transcelular o paracelular, posiblemente durante las infecciones intestinales o cuando existe un aumento de la permeabilidad intestinal, e interactúan en la lámina propia con las células presentadoras de antígenos.

- Factores genéticos. La enfermedad celíaca es un trastorno multigénico asociado con la expresión de los alelos específicos de la clase II del Complejo Mayor de Histocompatibilidad, HLA-DQ2 (DQA1*05 / DQB1*02) o HLA—DQ8 (DQA1*0301 / DQB1*0302), en la membrana celular de las células presentadoras de antígenos. HLA-DQ2 se expresa en más del 90\% de las personas con enfermedad celíaca. La expresión de estas moléculas HLA-DQ2 o HLADQ8 es necesaria, pero no suficiente, para desarrollar la enfermedad. Los resultados de estudios en hermanos (el riesgo de recurrencia para la enfermedad celíaca es del 10\%) y en gemelos idénticos (70\% de concordancia) sugieren que los genes HLA son solo parte la causa de la condición. Nuevas investigaciones, informan que la susceptibilidad adicional podría ser conferida por: COELIAC2 (5q31-33), que contiene grupos de genes de citoquinas (77); COELIAC3 (2q33) que codifica la molécula coestimuladora negativa CTLA4 (78) y COELIAC4 (19p13.1), que contiene la variante del gen IXB de miosina que codifica una miosina no convencional que altera la remodelación de la actina epitelial (79).

- Componente inmunológico. Las personas con EC desarrollan una intensa respuesta inmune a ciertas proteínas, que se mencionaron, contiene el gluten. La EC se caracteriza por un marcado aumento en los linfocitos $\mathrm{T} \mathrm{CD}^{+}$en el epitelio y de las células plasmáticas en la lámina propia.

En forma relevante, la mayoría de los pacientes no tratados con EC, presentan evidencia serológica de infección previa con el serotipo 12 de adenovirus. Este virus infecta el tracto gastrointestinal humano y una de sus proteínas tiene una región de secuencia de aminoácidos con homología a la gliadina. La exposición de personas genéticamente susceptibles a los cereales que contienen gluten, puede luego, estimular una reacción inmune contra la gliadina en el epitelio intestinal. En definitiva setienequedarunaconjuncióndeestosfactores, yaqueindividualmentenosonsuficientesparael desarrollo de la EC pero si necesarios.

\section{Fisiopatología}

Como se expresó anteriormente la EC se manifiesta en sujetos genéticamente predispuestos como una respuesta inmune frente al gluten ingerido. Esta respuesta inmune contiene una parte innata (efecto tóxico directo del gluten sobre el epitelio) y otra adaptativa (a través de los linfocitos TCD4 ${ }^{+}$ de la lámina propia o tejido subyacente), y las dos parecen ser las responsables del daño histológico en la mucosa intestinal $(81,82)$. Algunos fragmentos del gluten, como la gliadina, inducen una respuesta inmunológica innata, tóxica e inmediata, no relacionada con los linfocitos $\mathrm{T}$ ni con la presentación antigénica HLA-DQ2/8. Como consecuencia se desencadena estrés oxidativo, mediado principalmente por la formación de óxido nítrico, que se origina por la inducción de la óxido nítrico sintasa (iNOS) en los enterocitos dando como resultado la expresión de ligandos como MICA. La gliadina también es capaz de debilitar las uniones intercelulares situadas entre los enterocitos. Sin embargo, el principal mecanismo depende de la liberación de IL-15 por los enterocitos en situación de estrés $(81,83)$. Esta citoquina induce en los linfocitos intraepiteliales la expresión de NKG2D el cual es capaz de interactuar con su ligando, la molécula MICA de los enterocitos perpetuando el daño intestinal. La unión entre NKG2D y MICA induce apoptosis de los enterocitos, llevando a la desaparición de las microvellosidades y aplanamiento del epitelio intestinal (lesión histológica 
característica de la EC). Todo este proceso lleva a la activación de fenómenos de citotoxicidad en el epitelio, que junto con el debilitamiento de las uniones intercelulares contribuye al aumento de la permeabilidad intestinal y el paso del gluten hasta la lámina propia, donde se desencadena la respuesta adaptativa (80-82).

El mecanismo hipotético del desarrollo de la EC, puede ser dividido en 3 etapas principales (Figura 3):

1. Eventos luminales y tempranos de la mucosa, donde las características claves incluyen la ingestión de gluten por un individuo genéticamente susceptible. El gluten no es digerido completamente debido a su alto contenido de prolina y esto da lugar a un gran número de péptidos "gluten" no digeridos.

2. Respuesta inmunológica alterada. Los péptidos atraviesan la barrera epitelial hacia la lámina propia, donde se produce el encuentro con las transglutaminasas (TGasa) y las células inmunes que expresan los alelos HLA-DQ2 o HLA-DQ8 heterodímeros, ideales para unir péptidos ricos en prolina que contienen residuos de ácido glutámico cargados negativamente, los cuales son el resultado de la desaminación de la glutamina por la TGasa tisular.

3. Daño tisular. En una serie posterior de eventos, las células presentadoras de antígenos presentan algunos de estos péptidos a las poblaciones de células T CD4+, que se activan. Una vez activadas, las células T CD4+ secretan varias citocinas, incluidas IFN e IL-21.

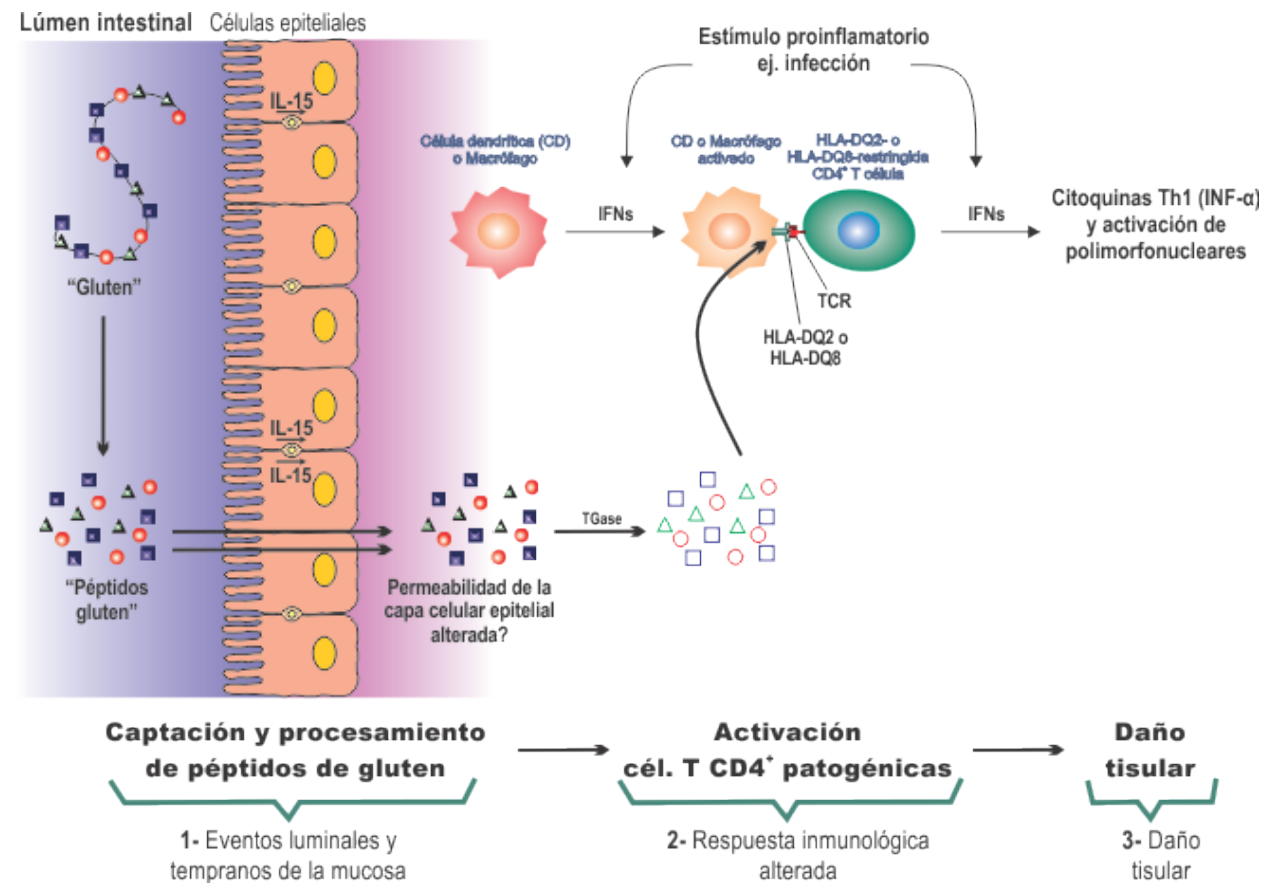

Figura 3: Mecanismo hipotético de la fisiopatogenia de la EC.

\section{Conclusiones}

Las células epiteliales intestinales crean barreas físicas y bioquímicas que separan los microbios de las células inmunes intestinales. Son capaces de detectar señales de ambas poblaciones y secretar factores humorales para mediar el equilibrio entre ambas y mantener la homeostasis intestinal. Sin embargo hallazgos recientes han sugerido que la barrera mucosa es el foco principal en la enfermedad celíaca. El sello histopatológico de la EC es la atrofia de las vellosidades del intestino delgado y la hiperplasia de las criptas. Dado que la arquitectura de la mucosa está muy alterada, el recambio de células epiteliales también es parte de la patogenia de la EC (66). La EC es una enfermedad global con una prevalencia que ha ido en aumento durante las últimas décadas. Sus muchas manifestaciones 
clínicas van desde síntomas gastrointestinales hasta síntomas no gastrointestinales o síntomas mínimos. La mayoría de los pacientes con EC permanecen sin diagnosticar, dado que presentan la forma silenciosa de la enfermedad. El efecto de la enfermedad en la salud de las personas con enfermedad celíaca silenciosa no está claro; sin embargo, podría explicar varios problemas de salud crónicos, como la osteoporosis, la infertilidad, las enfermedades autoinmunes y el empeoramiento de otras afecciones médicas graves. Por lo que es necesario aumentar la conciencia de su prevalencia y de sus diversas manifestaciones por parte del público en general y, en particular, de los profesionales de la salud. Por otra parte, la identificación de factores genéticos y ambientales y la comprensión de los mecanismos que desencadenan la respuesta inmune anormal al gluten ayudarán a comprender la justificación del amplio espectro clínico e histológico, y a largo plazo facilitar el diseño de tratamientos alternativos a la actual dieta sin gluten $(67,75)$.

Fuente de financiamiento: Fabiana García PIP Nº: 11220170101112CO, 2017-2019 Consejo Nacional de Investigaciones Científicas y Técnicas (CONICET). Secretaría De Ciencia y Tecnología-UNR. Resolución C.S Nº 1046/2018.

\section{Referencias bibliográficas}

1. Buckley A, Turner JR Cell Biology of Tight Junction Barrier Regulation and Mucosal Disease Cold Spring Harb Perspect Biol. 2018 ; 10(1):a029314.

2. Ahluwalia B, Magnusson MK, Öhman L. Mucosal immune system of the gastrointestinal tract: maintaining balance between the good and the bad. Scand J Gastroenterol. 2017, 52(11):1185-1193.

3. Mowat AM Anatomical basis of tolerance and immunity to intestinal antigens. Nat Rev Immunol. 2003, 3(4):331-341.

4. Mestecky J, Blumberg RS, Kiyono H, McGhee JR. The mucosal immune system. Fundamental Immunology, 5th edition Lippincott Williams \& Wilkins, 2005.

5. Belkaid Y, Naik S. Compartmentalized and systemic control of tissue immunity by commensals. Nat Immunol. 2013, 14(7):646-653.

6. Mason KL, Huffnagle GB, Noverr MC, et al. Overview of gut immunology. Adv Exp Med Biol. 2008; 635:1-14.

7. Brandtzaeg P, Kiyono H, Pabst R, et al. Terminology: nomenclature of mucosa—associated lymphoid tissue. Mucosal Immunol. 2008;1:31-37.

8. Mowat AM, Viney JL. The anatomical basis of intestinal immunity. Immunol Rev. 1997;156:145-166.

9. Belkaid Y. Tailored immunity at mucosae. Immunol Rev. 2014; 260(1):5-7.

10. Peterson LW, Artis D. Intestinal epithelial cells: regulators of barrier function and immune homeostasis. Nat Rev Immunol. 2014;14:141-153. Yap YA, Mariño E. An Insight Into the Intestinal Web of Mucosal Immunity, Microbiota, and Diet in Inflammation Front Immunol. 2018;9:2617.

12. McCracken VJ, Lorenz RG The gastrointestinal ecosystem: a precarious alliance among epithelium, immunity and microbiota Cell Microbiol. 2001,3(1):1-11.

13. Bevins CL, Salzman NH. Paneth cells, antimicrobial peptides and maintenance of intestinal homeostasis. Nat Rev Microbiol. 2011;9:356-368.

14. France MM, Turner JR The mucosal barrier at a glance J Cell Sci. 2017 Jan 15;130(2):307-314.

15. Odenwald MA, Turner JR The intestinal epithelial barrier: a therapeutic target? Nat Rev Gastroenterol Hepatol. 2017;14(1):9—21.

16. Weber CR. Dynamic properties of the tight junction barrier. Ann N Y Acad Sci. 2012;1257:77-84.

17. Odenwald MA, Turner JR. Intestinal permeability defects: is it time to treat? Clin Gastroenterol Hepatol. 2013; 11:1075-1083.

18. Abreu MT. Toll-like receptor signalling in the intestinal epithelium: how bacterial recognition shapes intestinal function. Nature Rev. Immunol. 2010;10,131-144.

19. Elinav E, Henao-Mejia J, Flavell RA. Integrative inflammasome activity in the regulation of intestinal mucosal immune responses. Mucosal Immunol. 2013;6, 4-13.

Broquet AH, Hirata Y, McAllister CS. Kagnoff MF. RIG-I/MDA5/MAVS are required to signal a protective IFN response in rotavirus-infected intestinal epithelium. J. Immunol. 2011;186,1618-1626.

21. Otte JM, Cario E, Podolsky DK. Mechanisms of cross hyporesponsiveness to Toll-like receptor bacterial ligands in intestinal epithelial cells. Gastroenterology. 2004;126, 1054-1070 Neish AS, Gewirtz AT, Zeng H et al. Prokaryotic regulation of epithelial responses by inhibition of IкB-a ubiquitination. Science. 2000; 289, $1560-1563$. Blander JM, Sander LE. Beyond pattern recognition: five immune checkpoints for scaling the microbial threat. Nature Rev. Immunol. 2010;12, 215-225. gene expression. J. Immunol. 2001;167,1882-1885. Nature Cell Biol. 2006;8, 1327-1336.

Okumura R, Takeda K. Maintenance of intestinal homeostasis by mucosal barriers. Inflamm Regen. 2018; 38:5 doi: 10.1186/s41232—018—0063—z. 
31. Vaishnava S, Yamamoto M, Severson KM, et al. The antibacterial lectin RegIII $\gamma$ promotes the spatial segregation of microbiota and host in the intestine. Science. 2011; 334, 255-258.

32. Mowat AM, Agace WW. Regional specialization within the intestinal immune system. Nat Rev Immunol. 2014;14:667-685.

33. Boyaka PN. Inducing Mucosal IgA: A Challenge for Vaccine Adjuvants and Delivery Systems J Immunol. 2017;199(1):9-16.

34. Shulzhenko N, Morgun A, Hsiao W, et al. Crosstalk between B lymphocytes, microbiota and the intestinal epithelium governs immunity versus metabolism in the gut. Nature Med. 2011;17:1585-1593.

35. Corthésy B. Multi—faceted functions of secretory IgA at mucosal surfaces. Front. Immunol. 2013;4: 185.

36. Macpherson AJ, Ko"ller Y, McCoy KD. The bilateral responsiveness between intestinal microbes and IgA. Trends Immunol. 2015. 36: 460-470.

37. Palm N W, de Zoete MR, Cullen TW, et al.. Immunoglobulin A coating identifies colitogenic bacteria in inflammatory bowel disease. Cell 2014;158:1000-1010.

38. Boullier SM, Tanguy KA, Kadaoui C, Caubet, P, et al Secretory IgA—-mediated neutralization of Shigella flexneri prevents intestinal tissue destruction by down—regulating inflammatory circuits. J. Immunol. 2009; 183: 5879-5885.

39. Fan X, Rudensky AY Hallmarks of Tissue-Resident Lymphocytes. Cell. 2016;164(6):1198-1211.

40. Artis D, Spits H. The biology of innate lymphoid cells. Nature. 2015; 517, 293-301.

41. Eberl G, Colonna M, Di Santo JP, McKenzie ANJ Innate lymphoid cells. Innate lymphoid cells: a new paradigm in immunology. Science. 2015; 348 , aaa6566

42. Godfrey DI, Uldrich AP, McCluskey J, Rossjohn J, Moody DB. The burgeoning family of unconventional T cells. Nat. Immunol. 2015; 16,1114-1123.

43. Wershil BK, Furuta GT. 4. Gastrointestinal mucosal immunity. J Allergy Clin Immunol. 2008;121:S380-S383; quiz S415.

44. Cheroutre H, Lambolez F, Mucida D. The light and dark sides of intestinal intraepithelial lymphocytes. Nat Rev Immunol. 2011;11:445-456.

45. Poussier P, Ning T, Banerjee D, et al. A unique subset of self-specific intraintestinal T cells maintains gut integrity. J Exp Med. 2002;195:1491-1497.

46. Cheroutre H. Starting at the beginning: new perspectives on the biology of mucosal T cells. Annu Rev Immunol. 2004;22:217-246.

47. Tlaskalova-Hogenova H, Stepankova R, Hudcovic T, et al. Commensal bacteria (normal microflora), mucosal immunity and chronic inflammatory and autoimmune diseases. Immunol Lett. 2004;93:97-108.

48. Reboldi A, Cyster JG. Peyer's patches: organizing B—cell responses at the intestinal frontier. Immunol Rev. 2016;271(1):230—45.

49. Fagarasan S, Kawamoto S, Kanagawa O, Suzuki K. Adaptive immune regulation in the gut: $\mathrm{T}$ cell—dependent and T cell—independent IgA synthesis. Annu Rev Immunol 2010;28:243-273

50. Victora GD, Nussenzweig MC. Germinal centers. Annu Rev Immunol 2012;30:429-457.

51. Weinstein PD, Cebra JJ. The preference for switching to IgA expression by Peyer's patch germinal center B cells is likely due to the intrinsic influence of their microenvironment. J Immunol 1991;147:4126-4135.

52. Pickard JM, Chervonsky AV. Sampling of the intestinal microbiota by epithelial M cells. Curr Gastroenterol Rep 2010;12:331-339.

53. Newberry RD, Lorenz RG. Organizing a mucosal defense. Immunol Rev. 2005;206:6-21.

54. Mabbott NA, Donaldson DS, Ohno H, Williams IR, Mahajan A. Microfold (M) cells: important immunosurveillance posts in the intestinal epithelium. Mucosal Immunol. 2013;6(4):666-77.

55. Buettner M, Bode U. Lymph node dissection—understanding the immunological function of lymph nodes. Clin Exp Immunol.2012;169:205-212

56. Regoli M, Bertelli E, Gulisano M, Nicoletti C. The Multifaceted Personality of Intestinal CX(3)CR1(+) Macrophages.Trends Immunol. 2017;38(12):879-887.

57. Jang MH, Kweon MN, Iwatani K, et al. Intestinal villous M cells: an antigen entry site in the mucosal epithelium. Proc. Natl.Acad.Sci.U.S.A. 2004; 101,6110-6115.

58. McDole JR, Wheeler LW, McDonald KG, et al. Goblet cells deliver luminal antigen to CD103+ dendritic cells in the small intestine. Nature. 2012; 483, 345-349.

59. Rescigno, M, Urbano M, Valzasina B, et al. Dendritic cells express tight junction proteins and penetrate gut epithelial monolayers to sample bacteria. Nat. Immunol.2001;2, 361-367.

60. Abbas AK, Lichtman AH, Pillai S. Cellular and molecular immunology. 8th ed. Philadelphia (PA): Elsevier Saunders; 2015.

61. Miyasaka M, Tanaka T. Lymphocyte trafficking across high endothelial venules: dogmas and enigmas. Nat Rev Immunol. 2004;4:360-370.

62. Ouyang W, Kolls JK, Zheng Y. The biological functions of T helper 17 cell effector cytokines in inflammation. Immunity. 2008;28:454-467.

63. Perez —Lopez A, Behnsen J, Nuccio S—P, Raffatellu M Mucosal immunity to pathogenic intestinal bacteria Nat Rev Immunol. 2016;16(3):135—48.

64. van Wijk F, Cheroutre H. Mucosal T cells in gut homeostasis and inflammation. Expert Rev Clin Immunol. 2010;6:559-566.

65. Radbruch A, Muehlinghaus G, Luger EO, et al. Competence and competition: the challenge of becoming a long-lived plasma cell. Nat Rev Immunol. 2006;6:741-750

66. Schumann M, Siegmund B, Schulzke JD, Fromm M. Celiac Disease: Role of the Epithelial Barrier. Review Cell Mol Gastroenterol Hepatol 2017;3(2):150-162

67. Glissen Brown JR, Singh P. Coeliac disease. Review. Paediatr Int Child Health. 2019;39(1):23-31.

68. Biagi F, Klersy C, Balduzzi D, et al. Are we not overestimating the prevalence of coeliac disease in the general population? Ann Med. 2010;42:557-561 
69. Mustalahti K, Catassi C, Reunanen A, et al. The prevalence of celiac disease in Europe: results of a centralized, international mass screening project. Ann Med. 2010;42:587-595.

70. Fasano A, Berti I, Gerarduzzi T, et al. Prevalence of celiac disease in at—risk and not—at—risk groups in the United States: a large multicenter study. Arch Intern Med. 2003;163:286-292.

71. Hovell CJ, Collett JA, Vautier G, et al. High prevalence of coeliac disease in a population—based study from Western Australia: a case for screening? Med J Aust. 2001;175:247-250.

72. Parra-Medina R, Molano-Gonzalez N, Rojas—Villarraga A, et al. Prevalence of celiac disease in latin america: a systematic review and metaregression. PLoS One. 2015;10:e0124040.

73. Singh P, Arora S, Singh A, et al. Prevalence of celiac disease in Asia: a systematic review and meta-analysis. J Gastroenterol Hepatol. 2016;31:1095-1101.

74. Dr. Julio C. Bai.Enfermedad Celíaca. Una actualización para clínicos.

75. Green PHR, Jabri B. Coeliac disease. Seminar. Lancet 2003, 362(9381):383-91.

76. Di Sabatino A, Corazza GR. Coeliac disease Lancet 2009, 25;373(9673):1480—93.

77. Greco L, Corazza GR, Babron MC, et al. Genome search in celiac disease. Am J Hum Genet 1998; 62: 669-75.

78. Holopainen P, Naluai AT, Moodie S, et al. Candidate gene region 2q33 in European families with coeliac disease. Tissue Antigens 2004; 63: $212-22$.

79. Monsuur AJ, de Bakker PI, Alizadeh BZ, et al. Myosin IXB variant increases the risk of celiac disease and points toward a primary intestinal barrier defect. Nat Genet 2005; 37: 1341-44.

80. Cardoso-Silva D, Delbue D, Itzlinger A, et al. Intestinal Barrier Function in Gluten—Related Disorders. Nutrients. 2019; $11(10): 2325$.

81. Vaquero L, Rodríguez-Martín L, León F, et al New coeliac disease treatments and their complications Gastroenterol Hepatol. 2018 ; 41:191—204.

82. Schuppan D, Junker Y, Barisani D Celiac disease: from pathogenesis to novel therapies Gastroenterology. 2009;137:1912-1933.

83. Di Sabatino A, Ciccocioppo R, Cupelli F, et al. Epithelium derived interleukin 15 regulates intraepithelial lymphocyte Thl cytokine production, cytotoxicity, and survival in coeliac disease. Gut. 2006;55:469—77.29. 